\title{
Investigating the Validity of Soft Tissue Signs on Lateral Ankle X-Ray to Aid Diagnosis of Achilles Tendon Rupture in the Emergency De-
} partment

\author{
Lowri Bowen $^{1 *}$, Rhodri Evans ${ }^{2}$, Owen Bodger ${ }^{3}$, Joshua Howard ${ }^{4}$ and Anne-Marie Hutchison ${ }^{5}$ \\ ${ }^{1}$ Gloucestershire Academy, Redwood Education Centre, Gloucester Royal Hospital, United Kingdom \\ ${ }^{2}$ Radiology Department, Hywel Dda Health Board, Swansea University, United Kingdom \\ ${ }^{3}$ School of Medicine, Swansea University, United Kingdom \\ ${ }^{4}$ Orthopaedic Department, Royal Gwent Hospital, United Kingdom \\ ${ }^{5}$ Department of Orthopaedic, Swansea Bay University Health Board, United Kingdom
}

*Corresponding author: Lowri Bowen, Undergraduate Department, Gloucestershire Academy, Redwood Education Centre, Gloucester Royal Hospital, Great Western Road, Gloucester, GL1 3NN, United Kingdom, E-mail: lowri.bowen@nbt.nhs.net

\begin{abstract}
Aims: To investigate the diagnostic validity of four radiological soft tissue signs Kager's sign (K), disruption to the tendon (D), loss of parallelism (P) and fusiform swelling of the tendon $(F)$ on a lateral ankle $x$-ray to aid Achilles tendon rupture diagnosis.

Methods: We retrospectively identified two groups of patients; Group A consisted of patients with an Achilles tendon rupture and Group B included patients with a clinically intact Achilles tendon but with a lateral ankle ligament sprain. Three clinicians independently reviewed all patients' $x$-rays for each of the radiological features under investigation to determine whether a rupture was present or not. Inter-rater and Intra-rater reliability were calculated using the Kappa coefficient (Kc.) To determine the predicted value of the signs sensitivity, specificity, positive predicted values and negative predicted values were calculated.

Results: 85 patients $x$-rays were included in this study; Group A $n=47$, Group B $n=38$. The most valid radiological sign appeared to be loss of parallelism (sensitivity $70 \%$, specificity $97 \%$, kappa 0.55-0.58).

Conclusion: Clinicians reviewing a lateral ankle x-ray of a patient with an acute ankle injury should review the x-ray for loss of parallelism between the tendon and skin; identification of this radiological sign may alert the clinician to the possible diagnosis of a ruptured Achilles tendon. Reviewing this may reduce the number of missed Achilles ruptures.
\end{abstract}

\section{Keywords}

Achilles tendon, Rupture, Diagnosis, X-ray, Ankle injury

\section{Introduction}

The Achilles tendon is the largest tendon in the body and risks rupture from running, jumping and sudden acceleration or deceleration [1]. It is vulnerable to injury because of its limited blood supply [2] and is the second most common ruptured supporting tissue in the body, after the quadriceps tendon [3] with an annual incidence of 8 per 100,000 in the general population [4]. A ruptured Achilles tendon is a traumatic condition which may present to the Emergency Department (ED).

Early diagnosis of Achilles tendon rupture is essential since delayed treatment may result in long term dysfunction including abnormal gait and chronic pain [3]. However, there are reports of up to $25 \%$ of Achilles tendon ruptures being missed by clinicians [2]. Diagnosis is usually made clinically and relies on an array of subjective and objective tests. Subjectively, patients may report a 'pop' or a 'kick' in the Achilles tendon region and objective tests include palpation of the Achilles tendon, a single leg heel raise and Simmonds test [5] which demonstrates a loss of dorsiflexion on calf squeeze in a ruptured tendon [6].

Despite Magnetic Resonance Imaging (MRI) being the gold standard for the diagnosis of Achilles tendon rupture, ultrasound is often used in the acute setting as it is cost effective, non-invasive and readily available

Citation: Bowen L, Evans R, Bodger O, Howard J, Anne-Marie H (2019) Investigating the Validity of Soft Tissue Signs on Lateral Ankle X-Ray to Aid Diagnosis of Achilles Tendon Rupture in the Emergency Department. Int J Foot Ankle 3:033. doi.org/10.23937/2643-3885/1710033

Accepted: September 12, 2019; Published: September 14, 2019

Copyright: (c) 2019 Bowen L, et al. This is an open-access article distributed under the terms of the Creative Commons Attribution License, which permits unrestricted use, distribution, and reproduction in any medium, provided the original author and source are credited. 
Table 1: Signs of lateral ankle $\mathrm{x}$-ray that have previously been associated with ruptured Achilles tendon.

\begin{tabular}{|c|c|}
\hline Sign on $x$ - ray & Description \\
\hline Kager's sign [8] & $\begin{array}{l}\text { Loss of sharp contour of the fat pad in Kager's triangle, margins become serrated and } \\
\text { indistinct. Triangle becomes smaller, less transparent and covered by a network like } \\
\text { shadow. }\end{array}$ \\
\hline Toygar's angle [9] & $\begin{array}{l}\text { Angle of the posterior skin surface curve. The angle diminishes in patients with rupture } \\
\text { and considered pathological if less than } 150^{\circ} \text {. }\end{array}$ \\
\hline Positive Arner's angle [10] & $\begin{array}{l}\text { Anterior contour of the Achilles tendon curves away from the calcaneus between the } \\
\text { insertion of the Achilles tendon, at the posterior aspect of the calcaneus, and the superior } \\
\text { aspect of the calcaneus. Proximal to the upper part of the calcaneus the anterior contour } \\
\text { shows a forward deviation, resulting in non-parallelism of the tendon and skin surface. }\end{array}$ \\
\hline Thickness of Achilles tendon [11] & A thickness of more than $8 \mathrm{~mm}$ is considered abnormal. \\
\hline $\begin{array}{l}\text { Tibio - first metatarsal angle - } \\
\text { indicator of ankle neutrality [12] }\end{array}$ & $\begin{array}{l}\text { Angle produced by a line drawn through the mechanical axis of the tibia and a line drawn } \\
\text { parallel to and bisecting the first metatarsal shaft. Neutral ankle defined as } \leq 100^{\circ} \text { - ankle } \\
\text { adopts more neutral position when Achilles tendon is ruptured. }\end{array}$ \\
\hline
\end{tabular}

Table 2: Definition of the modified x-ray signs investigated in this study.

\begin{tabular}{|l|l|}
\hline Kager's sign (K) & As described in Table 1. \\
\hline Disruption (D) & Disruption to the appearance of the Achilles tendon. \\
\hline Loss of parallelism (P) & Loss of parallelism between the tendon and skin. \\
\hline Fusiform (F) & An appearance of a fusiform swelling of the tendon (thickening of the tendon). \\
\hline
\end{tabular}

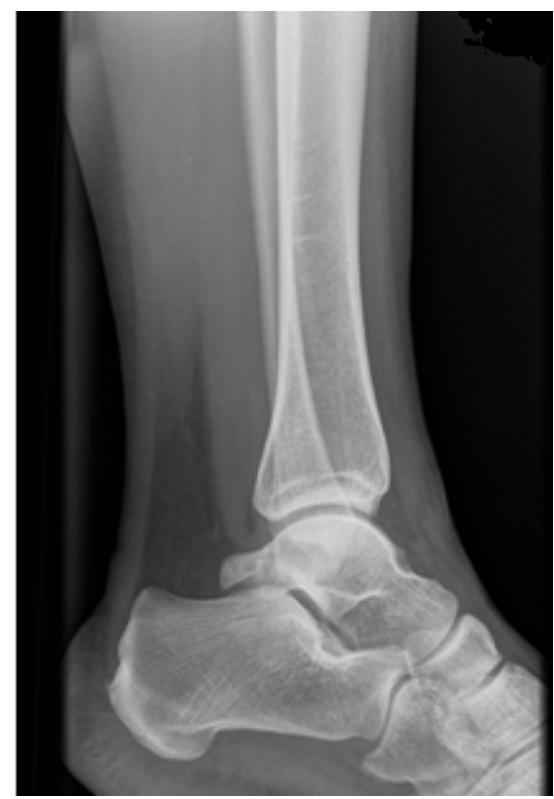

Figure 1: Appearance of normal lateral ankle x-ray.

[7]. However, X-rays are sometimes requested for these patients, usually to exclude bony injury in the emergency setting. Since an $x$-ray can be used to look at the bone, air and soft tissue, there may be soft tissue changes visible that could be used to aid the diagnosis of an Achilles rupture and potentially decrease the incidence of missed ruptures.

A literature review identified five radiological x-ray signs that have been described to diagnose an Achilles tendon rupture; these are described in Table 1 . To the authors knowledge, none of these tests have been investigated for reliability and accuracy.

The aim of this study was to investigate the diagnostic validity (reliability and accuracy) of radiological soft

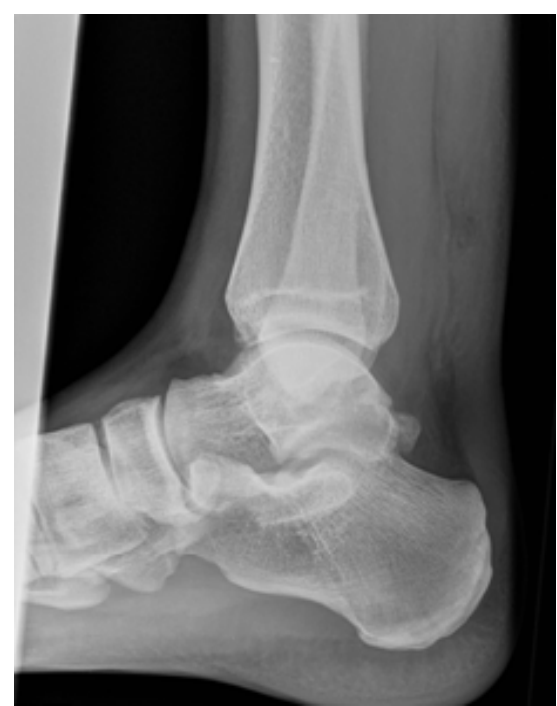

Figure 2: Lateral ankle x-ray of patient with Achilles tendon rupture.

tissue signs on a lateral ankle x-ray for an Achilles tendon rupture. Four radiological soft tissue features were investigated (Table 2); Kager's sign as described in Table 1 and the three others modified from the remaining four previously described. These modifications were made so that the signs could be applied by all clinicians, including those with limited radiological experience.

Please refer to Figure 1 and Figure 2 showing normal lateral ankle $x$-ray and lateral ankle x-ray of a patient with ruptured Achilles tendon. Figure 2 displays all signs explained above in Table 2.

\section{Methods}

\section{Study design}

A retrospective case control convenience study iden- 


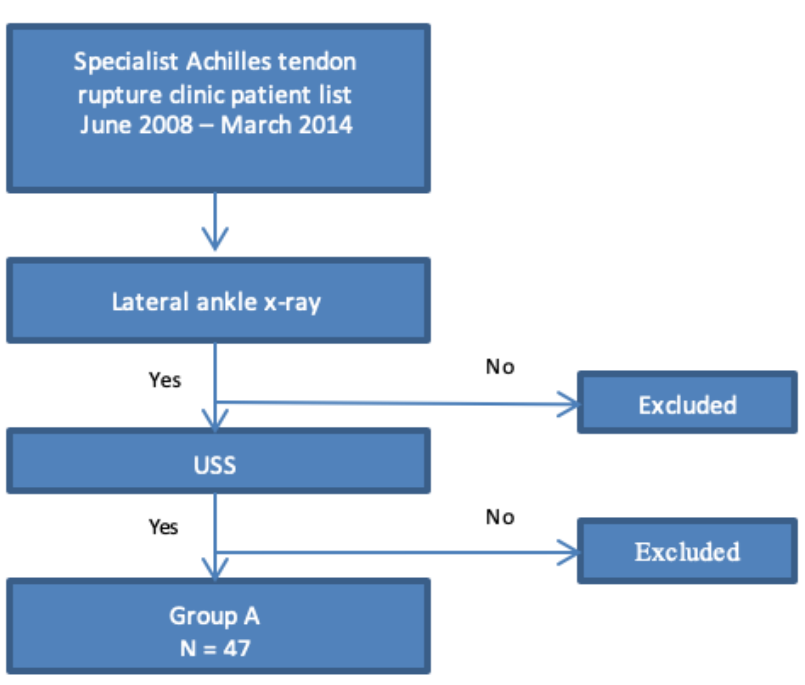

Figure 3: Flow chart showing participant selection into Group A.

Table 3: Interpretation of Kappa values [13].

\begin{tabular}{|l|l|}
\hline Value of Kc & Strength of agreement \\
\hline$<0.00$ & Poor \\
\hline $0.00-0.20$ & Slight \\
\hline $0.21-0.40$ & Fair \\
\hline $0.41-0.60$ & Moderate \\
\hline $0.61-0.80$ & Substantial \\
\hline$>0.81$ & Almost perfect \\
\hline
\end{tabular}

tifying soft tissue signs on lateral ankle $x$-ray to aid diagnosis of Achilles tendon rupture in the emergency department. The local ethics committee confirmed that ethical permission was not required for this study.

\section{Study population}

Two participant groups were identified for this investigation; Group A comprised of patients with an Achilles tendon rupture identified by a positive Simmonds test and confirmed by ultrasound scan, and Group B was a control group of patients who had not ruptured their Achilles tendon (determined by a negative Simmonds test) but had a lateral ankle ligament sprain. Both groups of patients had a lateral ankle X-rays at time of initial presentation; 47 lateral ankle $\mathrm{x}$-rays were retrieved from PACS for Group A, and 38 for Group B.

Group A were retrospectively identified from the clinical records of a specialist run Achilles tendon rupture clinic at our local hospital (between June 2008 and March 2014). Patients without both an ultrasound scan and lateral ankle $x$-ray were excluded.

Patients in Group B were retrospectively identified from the emergency department records of the same hospital (between January 2014 and June 2014). Included were all patients who were diagnosed with a lateral ligament ankle sprain and a negative Simmonds tests (indicating that the Achilles tendon was intact clinically).

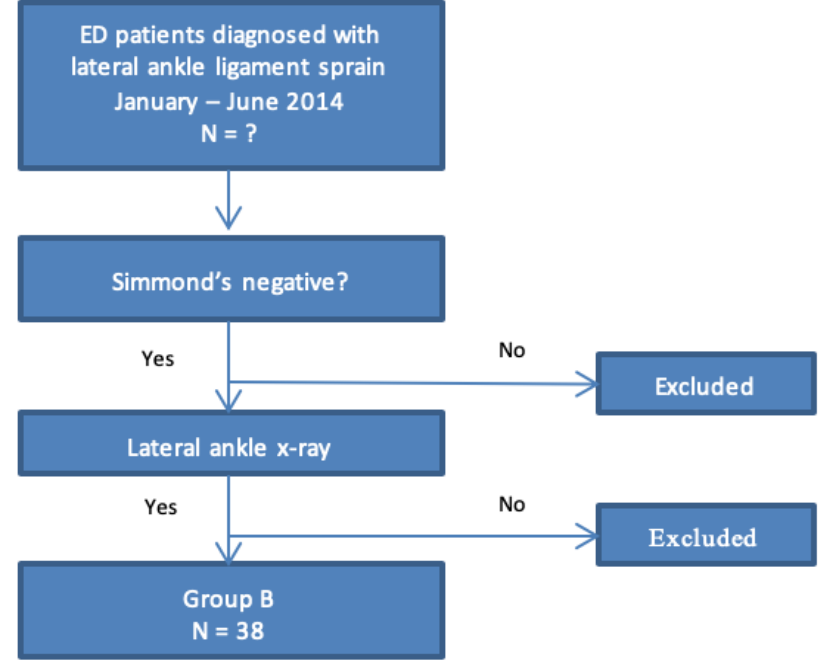

Figure 4: Flow chart showing participant selection into Group B.

All patients were over the age of 16 years and had a lateral ankle x-ray on arrival.

\section{Data collection}

All x-rays included in the study were anonymised and placed into a power point presentation in random sequence. These images were then reviewed by a consultant musculoskeletal Radiologist (C1), a senior physiotherapist (C2) and a medical student (C3) independently and blind to each other; all $x$-rays were reviewed via the PowerPoint. They reviewed the $x$-rays for each of the four radiological features ( $K, D, P$ and $F$ ) and documented on a proforma (Figure 1, Figure 2, Figure 3, Figure 4, Supplementary Table 1, Supplementary Table 2 and Supplementary Table 3) whether the Achilles tendon was ruptured or not. To investigate the intra-reliability, each reviewer conducted the same assessment of the $\mathrm{x}$-rays 24 hours later. To prevent recall bias, the $\mathrm{x}$-rays were reviewed in a different sequence for the second assessment.

\section{Statistical Analysis}

\section{Reproducibility}

The reproducibility (reliability) of the four $x$-ray signs for each clinician (intra-observer reliability) and between the three clinicians (inter-observer reliability) was calculated using the Kappa coefficient (Kc). The inter-observer reliability was measured from only the first diagnosis of each clinician and compared all clinicians with each other ( $\mathrm{C} 1$ and $\mathrm{C} 2, \mathrm{C} 1$ and $\mathrm{C} 3$, and $\mathrm{C} 2$ and $\mathrm{C} 3$ ). The strength of the agreement of the Kappa values was interpreted according to the values presented in Table 3.

\section{Accuracy}

In order to determine the accuracy of the signs, the sensitivity, specificity, positive predictive value (PPV) and negative predictive value (NPV) were calculated. 
Table 4: Reproducibility of $x$-ray signs with interpretation of Kappa value.

\begin{tabular}{|l|l|l|l|l|}
\hline X-ray Sign & Intra-observer agreement & \multicolumn{2}{l|}{ Inter-observer agreement } \\
\cline { 2 - 5 } & Kappa & Category & Kappa & Category \\
\hline Kager's sign (K) & 0.57 & Moderate & 0.36 & Fair \\
\hline Disruption (D) & 0.47 & Moderate & 0.21 & Fair \\
\hline Loss of Parallelism (P) & 0.55 & Moderate & 0.58 & Moderate \\
\hline Fusiform (F) & 0.46 & Moderate & 0.42 & Moderate \\
\hline
\end{tabular}

Table 5: Accuracy of x-ray signs; displaying sensitivity and specificity.

\begin{tabular}{|l|l|l|}
\hline Test & $\begin{array}{l}\text { Sensitivity } \\
(95 \% \text { confidence interval) }\end{array}$ & $\begin{array}{l}\text { Specificity } \\
\text { (95\% confidence interval) }\end{array}$ \\
\hline Kager's sign (K) & 84.8 & 71.9 \\
& $(77.1-90.1)$ & $(62.6-79.7)$ \\
\hline Disruption (D) & 48.6 & 97.4 \\
\hline Loss of parallelism (P) & $(40.0-57.2)$ & $(92.0-99.3)$ \\
\hline Fusiform (F) & 70.0 & 96.5 \\
& $(61.0-77.0)$ & $(90.7-99.9)$ \\
\hline & 53.6 & 94.7 \\
\hline
\end{tabular}

Table 6: Accuracy of X-ray signs; displaying Positive predicted values and Negative predicted values with $95 \%$ confidence intervals.

\begin{tabular}{|c|c|c|c|c|c|c|}
\hline \multirow[t]{2}{*}{ Test } & \multicolumn{3}{|l|}{ PPV } & \multicolumn{3}{|l|}{ NPV } \\
\hline & $\begin{array}{l}\text { Study } 55 \% \\
\text { prevalence }\end{array}$ & $25 \%$ prevalence & 75\% prevalence & $\begin{array}{l}\text { Study } 55 \% \\
\text { prevalence }\end{array}$ & $25 \%$ prevalence & 75\% prevalence \\
\hline Kager's sign & $\begin{array}{l}78.5 \\
(70.9-84.6)\end{array}$ & $\begin{array}{l}49.5 \\
(39.8-59.3)\end{array}$ & $\begin{array}{l}89.8 \\
(84.2-93.7)\end{array}$ & $\begin{array}{l}76.9 \\
(70.3-86.7)\end{array}$ & $\begin{array}{l}93.9 \\
(88.4-97.0)\end{array}$ & $\begin{array}{l}62.2 \\
(50.1-73.0)\end{array}$ \\
\hline Disruption & $\begin{array}{l}95.7 \\
(87.2-98.9)\end{array}$ & $\begin{array}{l}85.7 \\
(69.0-94.6)\end{array}$ & $\begin{array}{l}97.8 \\
(91.7-99.6)\end{array}$ & $\begin{array}{l}61.0 \\
(53.4-68.0)\end{array}$ & $\begin{array}{l}85.3 \\
(79.8-89.6)\end{array}$ & $\begin{array}{l}39.2 \\
(31.7-47.3)\end{array}$ \\
\hline $\begin{array}{l}\text { Loss of } \\
\text { parallelism }\end{array}$ & $\begin{array}{l}96.0 \\
(89.4-98.7)\end{array}$ & $\begin{array}{l}86.0 \\
(94.1-99.7)\end{array}$ & $\begin{array}{l}98.5 \\
(94.1-99.7)\end{array}$ & $\begin{array}{l}72.4 \\
(64.4-79.1)\end{array}$ & $\begin{array}{l}90.6 \\
(85.6-94.1)\end{array}$ & $\begin{array}{l}51.7 \\
(42.2-61.0)\end{array}$ \\
\hline Fusiform & $\begin{array}{l}92.5 \\
(83.8-96.1)\end{array}$ & $\begin{array}{l}76.7 \\
(61.0-87.7)\end{array}$ & $\begin{array}{l}97.1 \\
(91.1-99.2)\end{array}$ & $\begin{array}{l}62.8 \\
(55.1-69.9)\end{array}$ & $\begin{array}{l}86.2 \\
(80.6-90.4)\end{array}$ & $\begin{array}{l}40.8 \\
(32.9-49.2)\end{array}$ \\
\hline
\end{tabular}

This was done using only data from the first assessments in order to reflect clinical practice where decisions are made based on an initial $x$-ray review. The data of all three clinicians was combined $(n=225)$. For the predictive values we produced three different figures corresponding to the performance under a low, moderate and high prevalence level of a rupture (25\%, 50\% and $75 \%$ respectively), as well as the study population in which the prevalence was $55.3 \%$.

\section{Results}

The x-rays from 85 patients were included in this study, 47 patients had ruptured Achilles tendons (Group A) and 38 had lateral ligament injuries but no Achilles tendon rupture (Group B). Please refer to Figure 3 and Figure 4 showing flow of participant inclusion.

\section{Reproducibility}

Table 4 displays the Kappa values of the four x-ray signs.

When considering intra-rater reliability, $\mathrm{K}$ was shown to be the most reliable. When looking at the reliability between clinicians (inter-rater reliability), $\mathrm{P}$ and $\mathrm{F}$ were shown to be the most reliable.

\section{Accuracy}

Displayed in Table 5 and Table 6 is the data showing the accuracy of the radiological signs.

The radiological signs that demonstrated the highest accuracy for confirming the absence of an Achilles tendon rupture were $K$ and $P$. All four signs demonstrated high accuracy to confirm the presence of a rupture.

The tables displayed in the results section were condensed for the purpose of the report. Please refer to Supplementary Table 1, Supplementary Table 2 and Supplementary Table 3) which contains expanded versions of the tables with all the results from the study.

\section{Overall validity}

The overall validity of each of the radiological signs, that is both the accuracy and reproducibility (Kappa), needs to be considered when interpreting test results 
Table 7: X-ray signs ranked in order taking into consideration both reproducibility (Kappa) and accuracy (sensitivity and specificity).

\begin{tabular}{|l|l|l|l|}
\hline X-ray sign & Sensitivity & Specificity & Kappa Category \\
\hline Loss of parallelism (P) & 70.0 & 96.5 & Moderate \\
\hline Fusiform (F) & 53.6 & 94.7 & Moderate \\
\hline Kager's sign (K) & 84.8 & 71.9 & Fair \\
\hline Disruption (D) & 48.6 & 97.4 & Fair \\
\hline
\end{tabular}

in the clinical setting. The radiological feature that demonstrated the highest validity was $P$. None of the other features offered similar performance.

\section{Discussion}

Loss of parallelism was found to be the most valid radiological sign for diagnosing an Achilles tendon rupture demonstrating both good reliability $(\mathrm{Kc}=0.55)$ and accuracy. We would therefore recommend that all clinicians reviewing a lateral ankle $\mathrm{x}$-ray of a patient with an acute ankle injury should review the posterior soft tissue border of the achilles tendon, comparing the curve to the skin surface, to check for this feature.

Whilst the presence of a fusiform swelling, $F$, was shown to be reliable $(\mathrm{Kc}=0.42)$ and specific $(94.7 \%)$ it should be used with caution due to its low sensitivity (53.6\%) because its absence does not exclude injury (Table 7). It was found that the other two signs under investigation, $K$ and $D$, although highly specific, showed poor reliability and are therefore not recommended for clinical use.

All four signs showed moderate intra-observer reliability, however both $\mathrm{K}$ and $\mathrm{D}$ demonstrated low inter-observer reliability. This demonstrates that the individual clinicians had higher levels of agreement with themselves rather than with each other. This difference between intra and inter-observer reliability may be explained by how each clinician interpreted the definition of these two radiological signs and could reflect their subjective nature. It may have been that if the signs had been applied as initially described, without modification, then the reliability may have been improved.

To the authors knowledge this study is the first to investigate the validity of radiological features for an Achilles rupture therefore no comparison can be made with previous research.

Limitations of the study are recognised. Firstly, different reference standards were used for diagnosing an Achilles rupture in each of the two groups; all patients in Group A were diagnosed with an Achilles rupture by having an ultrasound scan investigation and a positive Simmonds test whilst the presence of an Achilles tendon rupture was excluded in the control group via Simmonds test only. This was due to the retrospective nature of the study. Ideally all patients in both groups would have an ultrasound scan but due to logistics and cost this would not have been possible. However, Simmonds test has been shown to be an accurate diagnostic test with a sensitivity and specificity of $96 \%$ and $93 \%$ respectively [14]. Therefore, we can be fairly certain that those in the control group with a rupture excluded via a negative Simmonds test were not misdiagnosed.

Secondly, it could be argued that since all the patients in the control group had a lateral ankle ligament sprain, these results can only be applied to this group of patients. It may be that patients in group B had other soft tissue or bony injuries that produced similar radiological features on x-ray to that of an Achilles rupture, confounding results. This warrants potential further investigation. In addition, calculating the cumulative statistical relevance of the presence of two or more concurrent signs may provide a more clinically significant diagnostic tool in practice.

In conclusion, this study investigated four radiological signs identifiable on a lateral ankle $x$-ray for their reliability and accuracy in diagnosing an Achilles tendon rupture. It was found that a soft tissue feature of loss of parallelism between the tendon and skin on a lateral ankle $\mathrm{x}$-ray is sufficiently reliable and accurate to be recommended in clinical use to aid diagnosis.

\section{Ethics Approval}

Not applicable.

\section{Clinical Trial Registration}

Not applicable.

\section{Funding}

This research received no specific grant from any funding agency in the public, commercial or not-forprofit sectors.

\section{Competing Interests}

None declared.

\section{Contribution}

All authors have made significant contribution to this paper. AMH planned the study and was responsible for collecting patient details and data. The study and data collection was then completed by As prew, LB and RE. $\mathrm{OB}$ was responsible for calculating the statistics used in this article. LB was the lead author of this paper. As prew, $\mathrm{RE}$ and $\mathrm{OB}$ contributed to the editing of the initial work for submission. JH contributed to the editing advice on all sections, and along with LB produced the final manuscript for submission. As prew and RE were both supervisors for the overall project. 


\section{References}

1. Ham P, Maughan KL (2014) Achilles tendinopathy and tendon rupture: Up To Date.

2. Mazzone MF, McCue T (2002) Common conditions of the achilles tendon. Am Fam Physician 65: 1805-1811.

3. Kerr J (2005) Achilles tendon injury: Assessment and management in the emergency department. Emerg Nurse 13: 32-38.

4. Suchak AA, Bostick G, Reid D, Blitz S, Jomha N (2005) The incidence of Achilles tendon ruptures in Edmonton, Canada. Foot Ankle Int 26: 932-936.

5. Dijk CNv, Karlsson J, Maffuli N, Thermann H (2008) Achilles tendon ruptures: Current concepts. ( $2^{\text {nd }}$ edn), DJO Publications, London, UK.

6. Scott BW, al Chalabi A (1992) How the Simmonds-Thompson test works. J Bone Joint Surg Br 74: 314-315.

7. Gulati V, Jaggard M, Al-Nammari SS, Uzoigwe C, Gulati $P$, et al. (2015) Management of achilles tendon injury: A current concepts systematic review. World J Orthop 6: 380386
8. Kager H (1939) Zur Klinik und diagnostik des achillessehnenrisses. Chirurg 11: 691-695.

9. Toygar O (1947) Subkutane ruptur der achillessehne (diagnostik und behandlungsergebnisse). Helv Chir Acta 3: 209-231.

10. Arner O, Lindholm A, Lindvall N (1959) Roentgen changes in subcutaneous rupture of the Achilles tendon. Acta Chir Scand 116: 496-500.

11. Cetti R, I Andersen (1993) Roentgenographic diagnoses of ruptured Achilles tendons. Clin Orthop Relat Res 286: 215221.

12. Kiely PD, Baker JF, Fat DL, Colgan G, Perera A, et al. (2011) Achilles tendon rupture must be excluded in the neutral, non-fractured ankle X-ray study. J Emerg Med 41: 718-722.

13. Petrie A, Sabin C (2009) Medical Statistics at a Glance. ( $3^{\text {rd }}$ edn), Wiley-Blackwell, UK.

14. Maffulli $N$ (1998) The clinical diagnosis of subcutaneous tear of the Achilles tendon. A prospective study in 174 patients. Am J Sports Med 26: 266-270. 
Supplementary Table 1: Proforma used by clinicians when reviewing the x-rays.

\begin{tabular}{|l|l|l|l|l|}
\hline Patient ID & Kager's (+l-) & Disruption (+/-) & Loss of Parallelism (+/-) & Fusiform (+/-) \\
\hline & & & & \\
\hline & & & & \\
\hline & & & & \\
\hline & & & & \\
\hline & & & & \\
\hline
\end{tabular}

$+=$ Achilles rupture present

Supplementary Table 2: Reproducibility of x-ray signs, including all Kappa values.

\begin{tabular}{|l|l|l|l|l|}
\hline & Intra-observer agreement & \multicolumn{4}{|l|}{ Inter-observer agreement Loss of Parallelism (+/-) Fusiform (+/-) } \\
\hline & C1, C2, C3 & C1 \& C2 & C1 \& C3 & C2 \& C3 \\
\hline X-ray Sign & Kappa & Kappa & Kappa & Kappa \\
\hline K & $0.57,0.69,0.65$ & 0.40 & 0.36 & 0.49 \\
\hline D & $0.47,0.56,0.62$ & 0.33 & 0.21 & 0.52 \\
\hline P & $0.55,0.76,0.55$ & 0.71 & 0.58 & 0.58 \\
\hline F & $0.46,0.67,0.59$ & 0.42 & 0.49 & 0.45 \\
\hline
\end{tabular}

C1 = Clinician 1; C2 = Clinician 2; C3 = Clinician 3. 


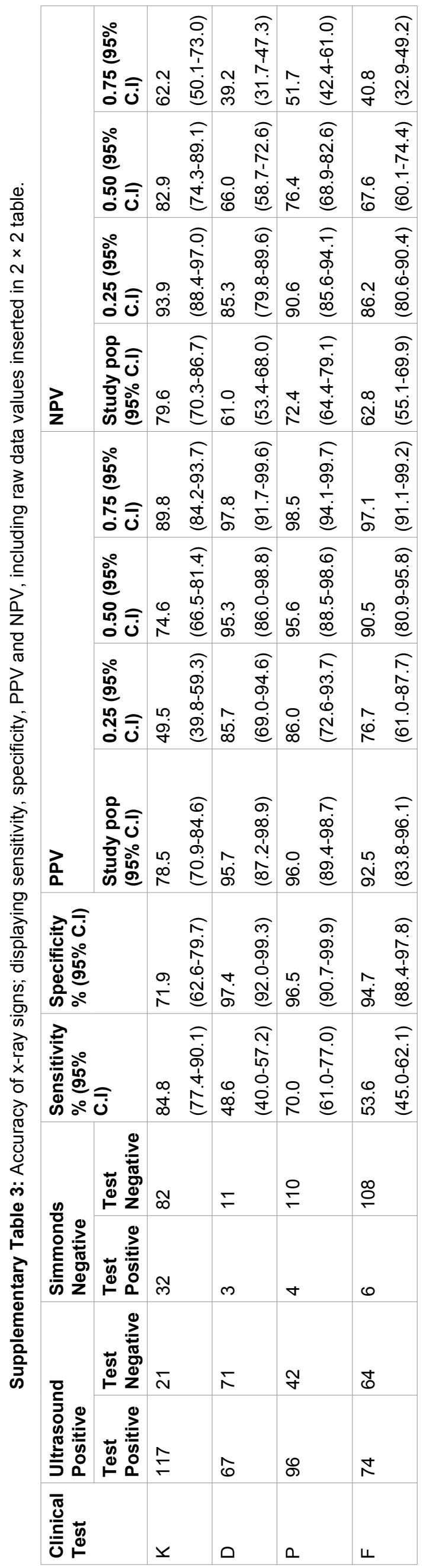

